\title{
Prevalence and correlates of depressive symptoms in HIV-positive patients: a cross-sectional study among newly diagnosed patients in Yaoundé, Cameroon
}

\author{
Rodrigue Minya L'akoa ${ }^{1,2+}$, Jean Jacques N Noubiap ${ }^{1,3^{*}+}$, Yixin Fang ${ }^{4}$, Félicien Enyime Ntone ${ }^{1,5}$ \\ and Christopher Kuaban 1,5,6
}

\begin{abstract}
Background: Depression is one of the most common neuropsychiatric complications of HIV disease, and in turn it is associated with worse HIV-related outcomes. Data on depression among HIV-infected patients in Cameroon are scarce. In this study, we report the prevalence and correlates of depressive symptoms among newly diagnosed HIV-infected patients in Yaoundé, Cameroon.

Methods: Interviews were conducted with 100 newly diagnosed HIV-infected patients at three referral hospitals of Yaoundé. Depression was assessed using the nine-item Patient Health Questionnaire (PHQ-9). A positive depression screen was defined as PHQ-9 score greater than 9.

Results: The overall prevalence of depressive symptoms was 63\% (95\% Cl: 53.2 to 71.8), the majority having symptoms corresponding to moderate depression. Multiple logistic regression analysis showed that probable depressed patients were more likely than those who were not depressed to have had experience of alcohol abuse (OR: 19.03, 95\% Cl 3.11-375.85; $p=0.0083$ ), and a 100 CD4 cells $/ \mathrm{mm} 3$ fewer was associated with a 2.9 times increase of the odds of probable depression ( $95 \% \mathrm{Cl} 1.88-4.84 ; \mathrm{p}<0.0001)$.

Conclusions: Our findings indicate a high prevalence of depressive symptoms in newly diagnosed HIV-infected patients in our setting, and their association with alcohol abuse and severe immunosuppression. This study also highlights the necessity to integrate mental health interventions into routine HIV clinical care in Cameroon.
\end{abstract}

Keywords: Depressive symptoms, HIV patients, Cameroon

\section{Background}

The HIV/AIDS pandemic has caused far-reaching effects in low-income countries. Sub-Saharan Africa has been particularly hard hit. In 2010, 68\% of all people living with HIV resided in Sub-Saharan Africa, a region with only $12 \%$ of the global population [1]. Sub-Saharan Africa also accounted for $70 \%$ of new HIV infections and $67 \%$ of AIDS-related deaths in 2010 [1].

\footnotetext{
*Correspondence: noubiapjj@yahoo.fr

${ }^{\dagger}$ Equal contributors

'Faculty of Medicine and Biomedical Sciences, University of Yaoundé I, Yaoundé, Cameroon

${ }^{3}$ Internal Medicine Unit, Edéa Regional Hospital, Edéa, Cameroon

Full list of author information is available at the end of the article
}

Cameroon is one of the 22 priority countries in the World Health Organization's Global Plan towards the Elimination of New HIV Infections among Children and Keeping Their Mothers Alive [2]. Situated in the Central Africa, Cameroon has the largest HIV/AIDS epidemic in this sub-region with an estimated HIV prevalence of 5.3\%, 610,000 people living with HIV, 48,000 adults newly infected and 37,000 AIDSrelated deaths reported in 2009 [3].

Depression is the most common neuropsychiatric complication of HIV disease [4]. HIV/AIDS and depression are projected to be the world's two leading causes of disability by 2030 [5]. Reports on the actual prevalence of depression in HIV-infected persons have varied widely, from $22 \%$ [6] to $71 \%$ [7]. With 350 million people affected worldwide [8], rates of depression are roughly two times greater in people

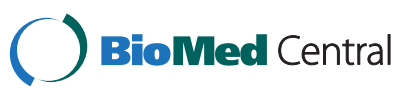


living with HIV than the general population (approximately $10 \%$ versus $5 \%$ ), as determined by a meta-analysis of published studies [9]. Depression is associated with increased health care utilization [10], decreased quality of life [11], and increased suicide rate among patients in primary care [12]. Among people living with HIV/AIDS, depression increases the likelihood of HIV transmission [13], is associated with poor adherence to antiretroviral therapy (ART) [14] leading to virologic failure [15], and may independently increase HIV progression [16]. It is therefore crucial to identify patients with depression for an appropriate management. Unfortunately in Cameroon, the management of HIV/AIDS emphasizes on somatic aspects of the disease and neglects psychiatric manifestations, and depression is therefore underdiagnosed. This is essentially due to the fact that mental health is not effectively integrated into HIV/AIDS clinical care.

A recent study among $\mathrm{HIV}$-infected patients on ART in a semi-urban centre in Cameroon reported that one in five participants met lifetime criteria for major depression disorders [17]. There are no other prior studies of depression prevalence among HIV patients in Cameroon. Our study aimed at determining the prevalence and correlates of depressive symptoms among newly diagnosed HIV-infected patients in Yaoundé, Cameroon.

\section{Methods}

\section{Ethical considerations}

This study was performed in accordance with the guidelines of the Helsinki Declaration and was approved by the National Ethics Committee of Cameroon (ethics approval $\mathrm{N}^{\circ} 008 / \mathrm{CNE} / \mathrm{SE} / 2011$ ). All participants provided written informed consent.

\section{Study design and setting}

We conducted an observational cross-sectional study in Yaoundé, Cameroon. Yaoundé is the administrative headquarters of the Centre Region and the political capital of the Republic of Cameroon. It is one of the two largest cities of Cameroon, with a population estimated at 2,000,000 inhabitants and characterized by a very great ethnic diversity; with almost all the 254 ethnic groups found in Cameroon represented [18].

The study was conducted between February and March 2011 in three HIV/AIDS treatment centers in Yaoundé which are among the pioneers in the fight against HIV infection in Cameroon. These centers are located in three referral hospitals: the Yaoundé Central Hospital that has the greatest pool of HIV-infected patients in Yaoundé, the Yaoundé Jamot Hospital that has the major centre for mental health in Yaoundé, and the Yaoundé General Hospital.

\section{Study population and sampling}

The target population comprised of newly diagnosed HIVpatients. To be eligible, patients had to be diagnosed HIV- positive within the past six months, aged 18 years or more, speaking English or French and consenting to participate in the study. We excluded patients presenting with behavioral disorders that may impede the ability to answer the study questionnaire. Participants were identified by convenient and consecutive sampling of eligible patients who came for consultation on the days that the investigator conducted recruitment at each site. Recruitment was pursued until the target convenient sample size of 100 was reached.

\section{Instruments and measures \\ Background characteristics}

Eleven background variables are: age, gender, education, area of residency (urban or rural), marital status, employment status, personal history of depression, family history of depression, alcohol abuse, last CD4 cell count and ART.

\section{Screening for alcohol abuse}

Alcohol abuse was diagnosed using the CAGE (Cutting down, Annoyance by criticism, Guilty feelings, Eyeopeners) questionnaire [19]. This instrument includes four questions: (i) Have you ever felt you should cut down your drinking? (ii) Have people annoyed you by criticizing your drinking? (iii) Have you felt bad or guilty about your drinking? (iv) Have you ever had a drink first thing in the morning to steady your nerves or get rid of a hangover (eye-opener)? Alcohol abuse is diagnosed if there are at least two positive responses. The CAGE has been shown to have a sensitivity of $84.4 \%$ and a specificity of $93.1 \%$ to detect alcohol-related problems at this threshold of 2 positive responses [20].

\section{Screening for depressive symptoms}

Depression was assessed using the nine-item Patient Health Questionnaire (PHQ-9), a validated depression screening tool which is based on the Diagnostic and Statistical Manual of Mental Disorders, 4th Edition (DSM-IV) criteria [21]. Depression severity is based on the PHQ-9 scores, which ranges from 0 to 27. A PHQ-9 score of greater than 9 has a sensitivity of $83 \%$ and a specificity of $92 \%$ for major depressive disorder diagnosis [22]. In this study, a positive depression screen was defined as PHQ-9 score greater than 9; scores of 10 to 14 defined a moderate depression; scores of 15 to 19 defined a moderately severe depression; scores greater than 20 defined a severe depression. Some studies have addressed the issue of using screening instruments such as PHQ-9 to diagnose psychiatric disorder [23]. Therefore, given inability to report prevalence of depression, we report the prevalence of depressive symptoms.

\section{Data analysis}

Data were coded, entered and analyzed using the Statistical Package for Social Science (SPSS) version 20.0 for 
Windows (SPSS, Chicago, Illinois, USA). We described quantitative variables using means with standard deviations (SD), and categorical variables using their frequencies and percentages. The $t$-test and the Chi-square test were used to compare quantitative and categorical variables respectively. Odds ratios (OR) with $95 \%$ confidence interval (CI) were used to evaluate the factors associated with depressive symptoms. The unadjusted ORs were calculated by univariate logistic regression. Furthermore, multiple logistic regression analyses were conducted based on five candidate models, which were compared using Akaike Information Criterion (AIC). The optimal model among the candidates is the one with the smallest AIC score [24]. This manuscript was written following STROBE guidelines for the reporting of observational studies [25].

\section{Results}

Background characteristics of study population

Among the 100 newly diagnosed HIV-infected participants, 52\% were female; their ages ranged from 18 to 62 years with a mean of 40.4 years $(S D=10.4)$. Their CD4 cell counts ranged from 9 to 474 cells $/ \mathrm{mm}^{3}$ with a mean of 234 ( $\mathrm{SD}=129)$. Sixty percent were living with a spouse, $54 \%$ were unemployed, and $76 \%$ were living in an urban area. The CAGE alcoholism screen was positive in $17 \%$ of the participants. Thirty-nine percent of participants had severe immunosuppression (CD4 cell count $<200$ ). Five percent had had a previous episode of depression. Other characteristics are depicted in Table 1.

\section{Prevalence and correlates of depression}

As shown in Table 2, 63\% (95\% CI: 53.2 to 71.8 ) of our study population had depressive symptoms, most of them having symptoms corresponding to moderate depression (46\% of the entire sample, and $73 \%$ of the depressed ones).

Table 3 presents unadjusted odds of depression with those background characteristics. Under Bonferroni correction for multiple comparisons (i.e., using significance level $0.05 / 11=0.0045)$, both alcohol abuse $(\mathrm{p}=0.003)$ and CD4 counts $(\mathrm{p}<0.0001)$ are significantly associated with probable depression. These results are confirmed by logistic regression analyses summarized in Table 4. We compared five candidates models (1: includes all variables; 2: includes all variables suspected in the literature; 3 : model 2 plus ART; 4: includes alcohol, CD4 cells count, and gender; 5: includes only alcohol and CD4 cells count) using Akaike Information Criterion (the smaller the better). It appears that model 1 was over-fit because of the largest AIC score associated with it. Moreover, the unusual changes in OR estimates from model 1 to 2 and 3 suggest that we should consider models sparser than model 1 . It seems model 5, including only alcohol and CD4, was the
Table 1 Background characteristics of 100 newly diagnosed HIV-positive patients in Yaoundé, Cameroon

\begin{tabular}{|c|c|c|c|}
\hline \multirow[t]{2}{*}{ Characteristic } & Male $(n=48)$ & Female $(n=52)$ & \multirow[t]{2}{*}{ P-value } \\
\hline & \multicolumn{2}{|c|}{ n (\%) or mean (SD) } & \\
\hline Age (years) & $42.4(10.3)$ & $38.7(10.3)$ & 0.07 \\
\hline \multicolumn{4}{|l|}{ Marital status } \\
\hline Single & $16(33.3)$ & $24(46.2)$ & 0.19 \\
\hline Couple & $32(66.7)$ & $28(53.8)$ & \\
\hline \multicolumn{4}{|l|}{ Education level } \\
\hline Primary & $16(33.3)$ & $20(38.5)$ & 0.76 \\
\hline Secondary & $17(35.4)$ & $19(36.5)$ & \\
\hline University & $15(31.3)$ & $13(25)$ & \\
\hline \multicolumn{4}{|l|}{ Employment status } \\
\hline Employed & $32(66.7)$ & $14(27)$ & $<0.001$ \\
\hline Unemployed & $16(33.3)$ & $38(73)$ & \\
\hline \multicolumn{4}{|l|}{ Area of residence } \\
\hline Urban & $33(68.7)$ & $43(82.7)$ & 0.10 \\
\hline Rural & $15(31.3)$ & $9(7.3)$ & \\
\hline
\end{tabular}

Personal past history of depression

$\begin{array}{cccc}\text { Yes } & 3(6.3) & 2(3.8) & 0.50 \\ \text { No } & 45(93.7) & 50(96.2) & \end{array}$

Family past history of depression

$\begin{array}{cccc}\text { Yes } & 2(4.2) & 0(0) & 0.22 \\ \text { No } & 46(95.8) & 52(100) & \end{array}$

Alcohol abuse

$\begin{array}{llll}\text { Yes } & 8(16.7) & 9(17.3) & 0.93\end{array}$

No $40(83.3) \quad 43(82.7)$

Receive antiretroviral treatment

\begin{tabular}{llll} 
Yes & $19(39.6)$ & $21(40.4)$ & 0.93 \\
No & $29(50.4)$ & $31(59.6)$ & \\
D4 cells count (cells $\left./ \mathrm{mm}^{3}\right)$ & $254(116)$ & $216(139)$ & 0.14 \\
\hline
\end{tabular}

best model among five candidates. Inference based on this model showed that probable depressed patients were more likely than those who were not depressed to have had experience of alcohol abuse (OR: 19.03, 95\% CI 3.11-375.85; $\mathrm{p}=0.0083$ ), and a $100 \mathrm{CD} 4$ cells $/ \mathrm{mm} 3$ fewer was asso-

Table 2 Prevalence of depressive symptoms among 100 newly diagnosed HIV-positive patients in Yaoundé, Cameroon

\begin{tabular}{lcc}
\hline Depression severity & Frequency or percentage* & $\mathbf{9 5 \%} \mathbf{~ C l}$ \\
\hline No depression & 37 & $28.2-46.8$ \\
Moderate depression & 46 & $36.6-55.7$ \\
Moderately severe depression & 16 & $10.1-24.4$ \\
Severe depression & 1 & $0.2-5.4$
\end{tabular}

* Since $\mathrm{N}=100$, frequencies and percentages are identical. No depression: PHQ-9 scores less than 9; Moderate depression: scores of 10 to 14; Moderately severe depression: scores of 15 to 19; Severe depression: scores greater than 20 . 
Table 3 Unadjusted correlates of depressive symptoms among 100 newly diagnosed HIV-positive patients in Yaoundé, Cameroon

\begin{tabular}{|c|c|c|c|c|}
\hline Measure & Total & Depression n (\%) & OR $(95 \% \mathrm{Cl})$ & P-value \\
\hline Age (years) & 100 & - & $0.99(0.96-1.01)$ & 0.34 \\
\hline \multicolumn{5}{|l|}{ Gender } \\
\hline Male & 48 & $26(54.2)$ & Referent & \\
\hline Female & 52 & $37(71.1)$ & $0.48(0.19-1.18)$ & 0.078 \\
\hline \multicolumn{5}{|l|}{ Marital status } \\
\hline Couple & 60 & $38(63.3)$ & Referent & \\
\hline Single & 40 & $25(62.5)$ & $0.96(0.39-2.40)$ & 0.93 \\
\hline \multicolumn{5}{|l|}{ Educational level } \\
\hline University & 28 & $18(64.3)$ & Referent & \\
\hline Less than university & 72 & $45(62.5)$ & $0.93(0.34-2.51)$ & 0.86 \\
\hline \multicolumn{5}{|l|}{ Employment status } \\
\hline Employed & 46 & $29(63)$ & Referent & \\
\hline Unemployed & 54 & $34(63)$ & $1.00(0.41-2.44)$ & 0.99 \\
\hline \multicolumn{5}{|l|}{ Area of residence } \\
\hline Urban & 76 & $46(60.5)$ & Referent & \\
\hline Rural & 24 & $17(70.3)$ & $1.58(0.53-4.82)$ & 0.36 \\
\hline \multicolumn{5}{|c|}{ Personal past history of depression } \\
\hline No & 95 & $61(64.2)$ & Referent & \\
\hline Yes & 5 & $2(40)$ & $0.37(0.04-2.93)$ & 0.26 \\
\hline \multicolumn{5}{|c|}{ Family past history of depression } \\
\hline No & 98 & $62(63.3)$ & Referent & \\
\hline Yes & 2 & $1(50)$ & $0.58(0.03-9.57)$ & 0.70 \\
\hline \multicolumn{5}{|l|}{ Alcohol abuse } \\
\hline No & 83 & $47(56.6)$ & Referent & \\
\hline Yes & 17 & $16(94.1)$ & $12.26(1.57-259.21)$ & 0.003 \\
\hline \multicolumn{5}{|l|}{ Antiretroviral treatment } \\
\hline No & 60 & $35(58.3)$ & $0.60(0.23-1.52)$ & \\
\hline Yes & 40 & $28(70)$ & Referent & 0.23 \\
\hline CD4 cells count* & 100 & - & $2.7(1.79-4.72)$ & $<0.0001$ \\
\hline
\end{tabular}

ciated with a 2.9 times increase of the odds of probable depression (95\% CI 1.88-4.84; p < 0.0001).

\section{Discussion}

Depression is a major problem in HIV-infected patients, because it can lead to poor adherence to ART, treatment failure, HIV progression and death [13-16]. Several years ago, it had been prominently reported that mental health must be integrated in global initiatives for HIV/AIDS, and that research on mental health and HIV should be a high priority, especially in less wealthy countries like Cameroon [26]. Unfortunately, there is still a scarcity of data on mental health in Cameroon. This study is only the second one on depression in HIV-infected patients in Cameroon. Accordingly, we sought to determine the prevalence and correlates of depressive symptoms among newly diagnosed HIV-infected patients in Yaoundé, Cameroon.

We found that $63 \%$ of our participants were probably depressed. In similar studies, Ouedraogo et al., Kaharuza et al. and Bhatia et al. respectively found depression prevalence of $51.3 \%$ in Burkina Faso, $47 \%$ in Uganda and $45 \%$ in USA [27-29]. Collaborating with these reports, our findings point out that depression is highly frequent among newly diagnosed HIV-infected patients. This high prevalence of depressive symptoms in our study population may be due to several factors. First, it may be reflective of psychological distress, precisely an adjustment reaction, due to recent notification of seropositivity. Supporting this hypothesis, Lyketsos et al. found that 
Table 4 Adjusted correlates of depressive symptoms among 100 newly diagnosed HIV-positive patients in Yaoundé, Cameroon

\begin{tabular}{|c|c|c|c|c|c|}
\hline \multirow[t]{3}{*}{ Variables (referent) } & \multicolumn{5}{|c|}{ Models } \\
\hline & \multicolumn{5}{|c|}{ OR (p-value) } \\
\hline & $(1)$ & $(2)$ & $(3)$ & (4) & $(5)$ \\
\hline Age & $1.03(0.28)$ & - & - & - & - \\
\hline CD4 cell count* & $3.30(<0.0001)$ & $2.85(<0.0001)$ & $3.12(<0.0001)$ & $2.85(<0.0001)$ & $2.9(<0.0001)$ \\
\hline Gender (male) & $2.42(0.23)$ & $1.93(0.27)$ & $2.05(0.24)$ & $1.95(0.20)$ & - \\
\hline Marital status (couple) & $1.17(0.78)$ & $0.89(0.83)$ & $0.88(0.82)$ & - & - \\
\hline Educational level (university) & $2.40(0.24)$ & - & - & - & - \\
\hline Employment status (employed) & $0.49(0.39)$ & $1.06(0.92)$ & $0.95(0.94)$ & - & - \\
\hline Area of residence (urban) & $2.25(0.25)$ & - & - & - & - \\
\hline Personal past history of depression (no) & $0.55(0.59)$ & - & - & - & - \\
\hline Family past history of depression (no) & $0.27(0.61)$ & - & - & - & - \\
\hline Alcohol abuse (no) & $44.66(0.003)$ & $19.79(0.01)$ & $22.96(0.0068)$ & $20.0(0.0084)$ & $19.03(0.0083)$ \\
\hline Antiretroviral treatment (yes) & $1.95(0.28)$ & - & $1.82(0.31)$ & - & - \\
\hline AIC score & 109.40 & 103.24 & 104.17 & 99.3 & 98.9 \\
\hline
\end{tabular}

* expressed by hundreds of cells $/ \mathrm{mm}^{3}$. OR adjusted odds ratio, AIC Akaike Information Criterion.

depression and adjustment disorders equally account for psychiatric morbidity among newly diagnosed HIVpatients in a medical outpatient HIV clinic [30]. On the contrary, other studies have shown only a modest increase in psychological distress immediately after notification of seropositivity, suggesting that adjustment does not play a major role in psychiatric morbidity at diagnosis of HIV infection [31]. Much more, Savetsky et al. reported that $71 \%$ of an urban cohort were depressed a mean of 840 days after diagnosis, which is beyond the timeframe of adjustment [7].

The high prevalence of depressive symptoms in our study may also be explained by severe immunosuppression in the participants. Thirty-nine percent of participants had severe immunosuppression (CD4 cell count $<200$ ), and univariate and multivariate logistic regression showed a significant association between severe immunodepression and depressive symptoms. Indeed, it has been shown that severe immunodepression and HIV-illness are predictors of depression [32-34]. It is therefore crucial to adequately treat depression in newly diagnosed HIV-patients to impact ART adherence which will in turn enhance physical health and quality of life and subsequently prevent long-term depression.

Seventeen percent of our participants were screened positive for alcohol abuse during the past six months. Consistent with previous reports [35], alcohol abuse strongly correlates with depressive symptoms in our study population. Factors such as unemployment and single status have been shown to strongly contribute to depression in HIV-patients $[28,29,36]$. In our study these factors were not significantly associated with depressive symptoms, emphasizing the great psychological burden of the HIV status itself in our participants.
Regardless of its correlates, the magnitude of probable depression reported in our study emphasizes the need to incorporate the management of depression in HIV-care guidelines in Cameroon. In their study in Bamenda, Cameroon, Gaynes et al. have reported that identification and successful management of major depression by a health care professional was infrequent [17]. Studies in developing countries have shown that proper interventions, including a cognitive-behavioral group plan and community-driven group interpersonal psychotherapy, can reduce depressive symptoms and may lead to a better quality of life for patients with HIV or patients in regions with a high prevalence of HIV $[37,38]$.

This study has some limitations. First, the study was conducted in an urban context, and patients from rural areas were in fact from the accessible rural outskirts of the town. Patients from isolated rural areas were not included in this study, and the impact of the place of residence (rural or urban) on the occurrence of depression was not well estimated. Secondly, the convenient sample size of 100 may also imply imprecision in our findings. However, our findings are consistent with several prior reports in similar settings. In addition, our data are from three referral centers for HIV/AIDS management and mental health in Yaoundé, thus supporting their generalizability especially in the urban context of Cameroon. Thirdly, we used high sensitivity and specificity diagnostic tools and criteria for depressive symptoms, but the PHQ-9 and the CAGE were validated in western settings and not in the Cameroonian HIV clinic settings. Questions related to the impact of depressive symptoms on function were not assessed. Finally, it would be very important to evaluate the impact of depression on the adherence to ART in 
Cameroon, since this data is completely lacking. Indeed, all the studies on factors associated with adherence to ART in Cameroon, surprisingly, did not assess depression [39].

\section{Conclusions}

Overall our findings indicate a high prevalence of depressive symptoms in newly diagnosed HIV-infected patients in Yaoundé, Cameroon, and their association with alcohol abuse and severe immunodepression. This highlights the need of efficient mental health interventions to be integrated into routine HIV clinical care in Cameroon. In this way, early screening and treatment of depression must be a major objective, since it may improve linkage to and retention in HIV care centers.

\section{Competing interests}

The authors declare that they have no competing interests.

\section{Authors' contributions}

RML designed the study, collected data, contributed to data analysis and revised the manuscript. JJNN designed the study, analyzed and interpreted data, drafted and revised the manuscript. YF contributed to data analysis and revised the manuscript. FEN contributed to the study design, data collection and revised the manuscript. CK supervised the study at each step. All the authors approved the final version of the manuscript.

\section{Acknowledgements}

We are grateful to all the patients who participated in this research.

\section{Author details}

${ }^{1}$ Faculty of Medicine and Biomedical Sciences, University of Yaoundé I, Yaoundé, Cameroon. ${ }^{2}$ Nguelemendouka District Hospital, Nguelemendouka, Cameroon. ${ }^{3}$ Internal Medicine Unit, Edéa Regional Hospital, Edéa, Cameroon. ${ }^{4}$ Department of Population Health, Division of Biostatistics, New York School of Medicine, New York, NY, USA. ${ }^{5}$ Department of Psychiatry, Yaoundé Jamot Hospital, Yaoundé, Cameroon. ${ }^{6}$ Faculty of Health Sciences, University of Bamenda, Bamenda, Cameroon.

Received: 18 February 2013 Accepted: 18 September 2013 Published: 22 September 2013

\section{References}

1. UNAIDS: UNAIDS world AIDS Day report, 2011. Joint United Nations programme on HIV/AIDS (UNAIDS); 2011. http://www.unaids.org/en/media/unaids/ contentassets/documents/unaidspublication/2011/jc2216_worldaidsday_ report_2011_en.pdf.

2. UNAIDS: Global plan towards the Elimination of New HIV infections among children by 2015 and keeping their mothers Alive 2011-2015. Joint United Nations programme on HIV/AIDS (UNAIDS); 2011. http://www.unaids.org/en/ media/unaids/contentassets/documents/unaidspublication/2012/ JC2385_ProgressReportGlobalPlan_en.pdf.

3. UNAIDS: UNAIDS report on the global AIDS epidemic 2010; 2010. http://www. unaids.org/documents/20101123_globalreport_em.pdf.

4. Tate D, Paul RH, Flanigan TP, Tashima K, Nash J, Adair C, Boland R, Cohen RA: The impact of apathy and depression on quality of life in patients infected with HIV. AIDS Patient Care STDs 2003, 17(3):115-120.

5. Mathers CD, Loncar D: Projections of global mortality and burden of disease from 2002 to 2030. Plos Med 2006, 3(11):2011-2030.

6. Campos LN, Guimaraes MD, Remien RH: Anxiety and depression symptoms as risk factors for non-adherence to antiretroviral therapy in Brazil. AIDS Behav 2008, 14:289-299.

7. Savetsky JB, Sullivan LM, Clarke J, Stein MD, Samet JH: Evolution of depressive symptoms in human immunodeficiency virus-infected patients entering primary care. J Nerv Ment Dis 2001, 189(2):76-83.

8. World Health Organisation: Health topics: depression. http://www.who.int/ mental_health/management/depression/flyer_depression_2012.pdf.
9. Ciesla JA, Roberts JE: Meta-analysis of the relationship between HIV infection and risk for depressive disorders. Am J Psychiatry 2001, 158:725-730.

10. Katon WJ: Clinical and health services relationships between major depression, de pressive symptoms, and general medical illness. Biol Psychiatry 2003, 54:216-226.

11. Sherbourne CD, Hays RD, Fleishman JA, Vitiello B, Mugruder KM, Bing EG, McCaffrey D, Burnam A, Longshore D, Eggan F, Bozzette SA, Shapiro MF: Impact of psychiatric conditions on health-related quality of life in persons with HIV infection. Am J Psychiatry 2000, 157:248-254.

12. Wulsin LR, Vaillant GE, Wells VE: A systematic review of the mortality of depression. Psychosom Med 1999, 61:6-17.

13. Treisman G, Angelino A: Interrelation between psychiatric disorders and the prevention and treatment of HIV infection. Clin Infect Dis 2007, 45(Suppl 4):S313-S317.

14. Sternhell PS, Corr MJ: Psychiatric morbidity and adherence to antiretroviral medication in patients with HIV/AIDS. Aust N Z J Psychiatry 2002, 36:528-533.

15. Paterson DL, Swindells $S$, Mohr J, et al: Adherence to protease inhibitor therapy and outcomes in patients with HIV infection. Ann Intern Med 2000, 133:21-30.

16. Leserman J: HIV disease progression: depression, stress, and possible mechanisms. Biol Psychiatry 2003, 54:295-306.

17. Gaynes BN, Pence BW, Atashili J, O'Donnell J, Kats D, Ndumbe PM: Prevalence and predictors of major depression in HIV-infected pateints on antiretroviral therapy in Bamenda, a semi-urban center in Cameroon. Plos One 2012, 7(7):e41699.

18. Bureau central des recensements et des études de population du Cameroun: Rapport de présentation des résultats définitifs de $3^{\text {ème }}$ recesement général de la population humaine. http://www.statistics-cameroon.org/ downloads/Rapport_de_presentation_3_RGPH.pdf.

19. Ewing JA: Detecting alcoholism. The CAGE questionnaire. JAMA 1984, 252(14):1905-1907.

20. Amaral RA, Malbergiera A: Evaluation of a screening test for alcoholrelated problems (CAGE) among employees of the campus of the University of Sao Paulo. Rev Bras Psiquiatr 2004, 26(3):156-163.

21. American Psychiatric Association (APA): Diagnostic and statistical manual of mental disorders, fourth Edition (DSM-IV) criteria for major depressive episode. Washington DC: APA; 1994

22. Kroenke K, Spitzer RL, Williams JB: The PHQ-9: validity of a brief depression severity measure. J Gen Intern Med 2001, 16:606-613.

23. Kinyanda E, Hoskins S, Nakku J, Nawaz S, Patel V: Prevalence and risk factors of major depressive disorder in HIV/AIDS as seen in semi-urban Entebbe district, Uganda. BMC Psychiatry 2011, 11:205.

24. Bumham KP, Anderson DR: Model selection and multimodel inference: a practical information-theoretic approach. 2nd edition. New York: Springer Verlag; 2002

25. von Elm E, Altman DG, Egger M, Pocock SJ, Gøtzsche PC, Vandenbroucke $J P$ : The strengthening the reporting of observational studies in epidemiology (STROBE) statement: guidelines for reporting observational studies. Bull World Health Organ 2007, 85:867-872.

26. Freeman $M$, Patel $V$, Collins PY, Bertolote J: Integrating mental health in global initiatives for HIV/AIDS. Br J Psychiatry 2005, 187:1-3.

27. Ouedraogo A, Sanou PT: Anxiété et dépression chez les personnes vivant avec le VIH en milieu africain à Ouagadougou, Burkina Faso. Psychopathol Africaine 2002, 31:333-344.

28. Kaharuza FM, Bunnell R, Moss S, Purcell DW, Bikaako-Kajura W, Wamai N: Depression and CD4 cell count among persons with HIV infection in Uganda. AIDS Behav 2006, 10:105-111.

29. Bhatia R: Person newly diagnosed with HIV infection are at high risk of depression and poor linkage to care: results from the steps study. AIDS Behav 2010, 8:1-10.

30. Lyketsos CG, Hanson A, Fishman M, McHugh PR, Treisman GJ: Screening for psychiatric morbidity in a medical outpatient clinic for HIV infection: the need for a psychiatric presence. Int J Psychiatry Med 1994, 24(2):103-113.

31. Cleary PD, Singer E, Rogers TF, Avorn J, Van Devanter N, Soumerai S, Perry S, Pindyck J: Sociodemographic and behavioral characteristics of HIV antibody-positive blood donors. Am J Public Health 1988, 78(8):953-957.

32. Burack JH, Barrett DC, Stall RD, Chesney MA, Ekstrand ML, Coates TJ: Depressive symptoms and CD4 lymphocyte decline among HIV-infected men. JAMA 1993, 270:2568-2573.

33. Adewuya AO, Afolabi MO, Ola BA, Ogundele OA, Ajibare AO, Oladipo BF: Psychiatric disorders among the HIV-positive population in Nigeria: a control study. J Psychosom Res 2007, 63:203-206. 
34. Freeman M, Nkomo N, Kafaar Z, Kelly K: Factors associated with prevalence of mental disorder in people living with HIV/AIDS in South Africa. AIDS Care 2007, 19:1201-1209.

35. Chandra PS, Ravi V, Desai A, Subbakrishna DK: Anxiety and depression among HIV-infected heterosexuals-a report from India. J Psychosom Res 1998, 45(5):401-409.

36. Nyamathi A, Heravian A, Zolt-Gilburne J, Zolt-Gilburna J, Sinha S, Ganguly K, Liu E, Ramakrishnan P, Marfisee M, Leake B: Correlates of depression among rural women living with AIDS in Southern India. Issues Ment Health Nurs 2011, 32(6):385-391.

37. Bolton P, Bass J, Neugebauer R, Verdeli H, Clouggherty KF, Wickramaratne P, Speelman L, Ndogoni L, Weissman M: Group interpersonal psychotherapy for depression in rural Uganda: a randomized controlled trial. JAMA 2003, 289(23):3117-3124.

38. Chan I, Kong P, Leung P, Au A, Li P, Chung R, PO LM, Yu P: Cognitivebehavioral group program for Chinese heterosexual HIV-infected men in Hong Kong. Patient Educ Couns 2005, 56(1):78-84.

39. Mbuagbaw L, Thabane L, Ongolo-Zogo P, Yondo D, Noorduyn S, Smieja M, Dolovich $\mathrm{L}$ : Trends and determining factors associated with adherence to antiretroviral therapy (ART) in Cameroon: a systematic review and analysis of the CAMPS trial. AIDS Res Ther 2012, 9(1):37.

doi:10.1186/1471-244X-13-228

Cite this article as: L'akoa et al.: Prevalence and correlates of depressive symptoms in HIV-positive patients: a cross-sectional study among newly diagnosed patients in Yaoundé, Cameroon. BMC Psychiatry 2013 13:228.

\section{Submit your next manuscript to BioMed Central and take full advantage of:}

- Convenient online submission

- Thorough peer review

- No space constraints or color figure charges

- Immediate publication on acceptance

- Inclusion in PubMed, CAS, Scopus and Google Scholar

- Research which is freely available for redistribution 